\title{
NARRATIVAS DE PROFESSORAS SOBRE TEXTOS IMPRESSOS E VIRTUAIS NO ENSINO DE HISTÓRIA PARA OS ANOS INICIAIS DO ENSINO FUNDAMENTAL
}

\author{
TEACHER'S NARRATIVES ON PRINTED AND VIRTUAL TEXTS FOR THE \\ HISTORY TEACHING TO EARKY GRADES OF ELEMENTARY SCHOOL
}

\author{
Magda Madalena Tuma ${ }^{1}$ \\ Kátia Maria Abud ${ }^{2}$
}

\begin{abstract}
RESUMO: O movimento cognitivo do sujeito para a narrativa de seu percurso e projeto gera a construção de uma 'figura de $\mathrm{si}^{\prime}$ onde se anuncia como sujeito de uma História da qual é o autor e articulador das dimensões do presente, do passado e do futuro. Nesta perspectiva, para a produção de depoimento-documento por 15 professoras dos Anos Iniciais do Ensino Fundamental da rede municipal de Londrina, optamos pela proposição dos ateliês biográficos de Delory- Momberger (2008). Este exercício de comunicação intercultural propiciou o reconhecimento do sentido atribuído aos textos virtuais na relação com textos impressos para o Ensino de História, onde constatamos que os livros utilizados para o Ensino de História, ao serem transformados em textos eletrônicos, são superestimados na ausência da consideração de que não é o suporte dado ao livro (impresso ou eletrônico) que gerará melhores abordagens e/ou ampliará seu potencial para a aprendizagem histórica nos Anos Iniciais.
\end{abstract}

Palavras-chave: Narrativas de professores. Ensino de História. Aprendizagem histórica. Anos Iniciais.

\begin{abstract}
The subject's cognitive movement for the narrative of his/her journey and project generates the construction of a "self figure" where he/she introduces himself/herself as the subject of a History, of which they are authors and articulators of the present, past and future dimensions. Within this perspective, we opted for the biographical workshops of Delory- Momberger (2008) to produce a testimony document of 15 teachers from public Elementary Schools in Londrina. This intercultural communication exercise provided the recognition of the meaning attributed to virtual texts in their relationship with History
\end{abstract}

1. Professora Associada do Departamento de Educação da UEL. Doutora em Educação pela UNICAMP.

2 Docente do Programa de Pós-Graduação da Faculdade de Educação da USP. Doutora em História pela USP. 
Teaching texts, where we realized that books used to teach History, when transformed into electronic texts, are overestimated since it is not the support they give to the book (printed or electronic) that will generate better approaches and/or increase their potential to learn History in the Early Grades.

Key words: Teacher's Narratives. History Teaching. Historical learning. Early Grades.

\section{Introdução}

O caráter narrativo das representações históricas para Kocka (2002) representa avanço na historiografia recente ao possibilitar estudos sobre os estratos mais profundos da realidade histórica, o que não impede críticas que não são de todo carentes de razão ao se considerar que:

[...] entre algunos defensores de la $<<$ historia de la cotidianeidad $>>$, em la prevalece la ilusión de la $<<$ historia desde dentro y desde abajo $>>$ ajena a toda teoria. De acuerdo con esta posición, el historiador debe reconstruir las experiências da la gente de a pie con comprensión y simpatía (KOCKA, 2002, p. 99).

Esta reflexão de Kocka (2002) nos auxilia para situar que a historiografia sustentará os apontamentos de limites e possibilidades teóricas presentes nas conceitualizações das professoras, sendo estas reconhecidas como elaborações que nos aproximam a alguns dos sentidos que expressam sobre a História, Ensino de História e os artefatos tecnológicos.

Quais os sentidos atribuídos à História aprendida, ensinada e projetada, são as questões que norteiam este estudo que faz parte de projeto mais amplo, o qual abrange 15 professoras dos Anos Iniciais do Ensino Fundamental, que elaboraram três narrativas cada uma, totalizando, assim, 45 narrativas, as quais tendo o tempo presente, como ponto de intercessão entre o passado e o futuro, nos permitiram aproximação ao que conhecem, fazem e projetam.

A duração foi o primeiro critério para a análise ao possibilitar "[...] desde um presente pasado (no desde un pasado pasado) hasta el futuro presente, quizás hasta el futuro futuro". (KOSELLECK, 2001, p. 118), ou 
seja, uma análise não estanque no que se refere às relações entre as três dimensões temporais, assim como a inserção da mudança como aquela que:

[...] puede igualmente establecerse como el trânsito desde um pasado pasado a um presente pasado (piénsese por ejemplo em las instituciones feudales y su disolución en el curso de la secularización o en la liberación de los agricultores) o desde el futuro pasado de mundos anteriores hasta nuestro pasado presente (piénsese por ejemplo em las utopias de la Revolución francesa, cuyas esperanzas todavia están presentes). (KOSELLECK, 2001, p. 118-119).

Somada à duração e à mudança está a unicidade que "[...] se deriva de la sucesión de los presentes com sus pasados y futuros que se modifican" (KOSELLECK, 2001, p. 119).

Para este estudo, tais norteamentos remetem ao intento de trazer os sentidos que as 15 professoras expressaram no bojo das mudanças tecnológicas da atualidade e que utilizam para o Ensino de História em suportes textuais, como o impresso e o virtual, na consideração de que:

Toda vida humana esta constituída por experiencias, bien sean nuevas y sorprendentes 0 , por el contrario, de naturaleza repetitiva. Se necesitan conceptos para poder tener o acumular experiências e incorpora-las vitalmente. Son necessarios para fijar las experiencias, que se diluyen, para saber qué sucedió y para conservar el pasado em nuestra lenguaje" (KOSELLECK, 2006, p. 29).

\section{Articulando saberes e práticas em tentativas de mudanças para o Ensino de História}

Sendo as discussões historiográficas as referências para aproximação aos sentidos atribuídos pelas professoras no que se refere aos textos impressos de História, a professora Laura (50 anos) apresentou questionamento sobre o 'livro de História' como "fonte da verdade" ao dizer que " $A$ história ensinada nos livros nem sempre condiz com o que aprendi que não era verdadeiro". Sem definir se tinha por referência o livro didático (o que consideramos mais provável), a professora nos apresenta uma questão da historiografia que pode ter interpretações variadas e que, conforme Le Goff (2003) expõe a dualidade "[...] da história como história- 
realidade e história- estudo desta realidade" (LE GOFF, 2003, p. 21).

Mas o que é a História? Esta é uma questão tão ampla e complexa que não será objeto deste estudo, o qual visa reconhecer o sentido das representações constituídas pelas experiências da vida prática, tanto na esfera teórica como em seus fazeres, na consideração de que tais esferas estão articuladas, pois, o conhecimento histórico traz significados que repercutem sobre o 'agir humano', mesmo não se alinhando de maneira clara às correntes historiográficas.

Os historiadores buscam ou são orientados "[...] pelas modificações temporais no passado do homem e de seu mundo, mas não de forma a explicar singularmente cada caso de mudança examinado" (RÜSEN, 2007, p. 31), portanto é o rompimento com o acontecimento histórico como "visível e legível", já questionado por Lucien Febvre (1952), assim como por Braudel (1978), que é levado em consideração pelo historiador, o qual:

[...] não mais parte da raridade (restos do passado) para chegar a uma síntese (compreensão presente), mas que parte de uma formalização (um sistema presente) para dar lugar aos "restos" (indícios de limites e, portanto, de um passado que é produto do trabalho). (CERTEAU, 2007, p. 86).

Ana (29 anos), ao dizer que "Não sei conceituar História, me interesso por fatos históricos. Fatos históricos: coisas que aconteceram e marcaram o mundo. Acompanho História vendo fatos na internet", apresenta experiência pessoal destituída da compreensão de que os fatos são resultantes de procedimento que exige do historiador:

[...] operação histórica que consiste, após ter reunido, criticado e dissecado o conjunto de documentos disponíveis, em estabelecer encadeamentos entre os diversos componentes do objeto estudado - de acordo com um método adaptado a cada caso - e a construir um discurso atribuindo-Ihe coerência e sentido. (BÉDARIDA, 1998 , p. 149).

Atribuindo à massa de informações despejadas pela internet a condição de 'fato histórico' a professora exalta esta forma de 'comunicação' com o mundo e não percebe que "[...] instala-se, assim, numa névoa espaço - temporal que degrada e decompõe a relação fecunda entre o aqui e o ali, o próximo e o distante, o dentro e o fora, o central e o periférico, o 
antes, o agora e o depois" (CHESNAUX, 1996, p. 30).

Com base em Chartier (2010), podemos, ainda, considerar que as transformações trazidas pela 'textualidade eletrônica' e que repercutem sobre o leitor, não alteram para o historiador a necessidade das técnicas da prova e de validação dos argumentos em discursos históricos que permitem múltiplas "ligações hipertextuais". O que muda é a relação ágil e crítica do leitor com o texto e seu autor, e a ampliação de produções que se apropriaram da linguagem histórica sem obedecer a seus procedimentos, as quais se apresentam como históricas e/ou como fontes históricas credenciadas. Esta condição se torna problemática ao repercutir sobre a operação cognitiva do leitor, trazendo a compreensão parcial ou equivocada. (CHARTIER, 2010, p. 60-61).

Além deste aspecto, reconhecer que 0 fato histórico traz em si condições que devem ser buscadas no passado, e que nem por isso se dissocia do tempo presente, significa reconhecer que:

\begin{abstract}
A operação histórica consiste em recortar o dado segundo uma lei presente, que se distingue do seu "outro" (passado), distanciando-se com relação a uma situação adquirida e marcando, assim, por um discurso, a mudança efetiva que permitiu este distanciamento. (CERTEAU, 2007, p.93).
\end{abstract}

Assim, cinco professoras utilizaram o termo 'fato histórico' em sentido que não é o da historiografia, assim como o termo acontecimento não é reconhecido por duas professoras como aquele que "É o postulado e o ponto de partida - mas também o ponto cego - da compreensão" (CERTEAU, 2007, p. 103).

Mas, chama atenção o esforço empreendido por sete professoras para a elaboração da conceituação de História, assim como das demais (oito) que de maneira pontual relacionaram a História ao passado, ao antigo, ao velho, aos registros, à vida, ao homem, à mudança, ao presente e ao futuro, nos indicando a presença de princípios caros à historiografia, mas sem o reconhecimento da História como operação pela qual se presentifica o passado como "aquilo que falta" assim como "[...] o lugar que ela destina ao passado é igualmente um modo de dar 'um lugar ao futuro'" (CERTEAU, 2007, p. 93).

"Fazer a História" não é a prática e nem a formação das professoras, 
mas para este primeiro movimento do estudo fez parte do desafio reconhecer, minimamente, o que entendem sobre História para a articulação entre as narrativas e as práticas do Ensino de História na relação com os artefatos tecnológicos, neste caso, os textos impressos e virtuais. Assim, o que se percebe é que o movimento do historiador para a constituição de suas fontes e reinterpretação do passado, não é percebido pelas professoras como uma operação histórica que exige reunir, articular e criticar para a construção de argumentações que compõem o discurso histórico.

O tempo histórico é interpretado como parte da vida e relacionado a um determinado tempo, ao antes e depois, periodização, evolução e tecnologia. A História como disciplina escolar é apontada como importante e vivenciada em práticas inadequadas no decorrer do próprio processo formativo. Reconhecendo ter entendimento limitado da teoria da História e que tal condição prejudica o redimensionamento do Ensino de História que realizam, indicam, nestas experiências, a presença massiva de estudos relacionados às datas comemorativas, personagens, guerras e política, além dos estudos sobre a História Regional e à Antiguidade.

Neste entrecruzamento de argumentos sobre as estratégias e práticas escolares que marcaram suas trajetórias, as professoras indicam a ausência da relação da História com a 'vida' e dificuldades para a explicação teórica, reconhecendo que, em suas trajetórias, tiveram acesso a determinados fundamentos históricos, os quais permaneceram sem esclarecimentos, gerando o reconhecimento da 'falta' perante o saber histórico do qual se apropriaram.

Tentar superar é movimento que expressam, quando dizem:

"Somos seres históricos. Isso é primordial. De onde ele veio. De onde eu vim. A História consegue relacionar. O ambiente em que eu vivo tem uma história" (Renata, 36 anos).

"A História é imprescindível para a consciência histórica do aluno" (Laila, 36 anos).

"Eu acho que a história é importante porque vai se conhecendo a si 
próprio" (Ecinel, 50 anos).

Tais posicionamentos trazem, sucintamente, argumentos para as tentativas de mudança que intentam para o Ensino de História por meio de dramatizações, brincadeiras, árvore genealógica, estudo de campo, linha do tempo, uso do vídeo, da internet e outros, como exemplifica Marjorie (47 anos):

Antes ficávamos presos aos livros. Hoje valorizamos o que o aluno vive: família, bairro, escola, sociedade, a realidade do aluno [...] usamos fotografia, entrevista com os pais, comparação através da foto, eles trouxeram vestuário e objetos. Fizemos discussão comparando a História de cada um, construindo valores, identidades e senso crítico do passado.

Afirmando a importância do Ensino da História e considerando que suas experiências não foram adequadas, passamos, agora, à análise da História que as professoras ensinam e como os textos impressos e virtuais se inserem no que se refere à capacidade de mudança empreendida (que empreendem) em sua ação pedagógica.

Lahire (2002) nos ensina que no contexto de mobilização do passado no presente as pessoas podem dar "[...] vida àquilo que permaneceria em estado de letra morta, mas inversamente, porque é colocado na presença do objeto, da situação, da instituição, do lugar, etc.[...]". (LAHIRE, 2002, p. 71).

Renata é uma professora que demonstra preocupação em fazer com que o ensino adquira sentido para a criança, mas em sua narrativa não detalha suas ações, apenas comentando que " $A$ criança é visual por mais que a gente parta da rua, do bairro... A criança não sabe contar o que aconteceu ontem". Nesta colocação ela não nos permite identificar, com maior clareza, se a entende "[...] como processo cognitivo [...] ou se insere "[...] pontos de vista emocionais, estéticos, normativos e de interesses" (RÜSEN, 2010, p. 44), o que se constata é que ela atribui incapacidade à criança pela faixa etária ao entendimento de supostos raciocínios exigidos pelo aprendizado histórico, manifestação feita por outras professoras, também, nos seguintes termos:

"As dificuldades que sinto é por não poder aprofundar mais no conteúdo por 
conta da idade e maturidade dos alunos" (Patrícia - $1^{\circ}$ ano).

"A dificuldade é que muitas vezes é difícil fazer estudar a relação da necessidade deste conteúdo à sua vida, o que muda" (Flávia - Profa Ed. Física).

"A dificuldade é que muitos alunos desconheciam as palavras" (Cecília, $1^{\circ}$ ano).

Considerando a aprendizagem histórica difícil para as crianças que têm idade entre 5 e 9 anos, entendem como empecilho o não reconhecimento de elementos da transformação histórica que se evidenciam na relação da vida presente com o passado, assim como pela ausência da escrita.

O passado não está disponível de maneira clara para ninguém, mas sua compreensão não pode ser limitada pela escrita, pois a memória, que não é ato de pura reprodução, revela pensamentos que podem não alocar de forma fixa e em determinado lugar e tempo os acontecimentos. Assim, ao se limitar a aprendizagem histórica pela escrita, se revela a compreensão de que a História não vai além do reconhecimento de acontecimentos, datas e personagens do passado, ou seja, que a História pode ser entendida como a exposição de "[...] uma população de mortos - personagens, mentalidades ou preços". Uma apresentação que gera a "galeria" que simplifica o discurso histórico. (CERTEAU, 2007, p. 106).

O que se apresenta como ausente no entendimento das professoras é que a aprendizagem histórica se refere a experiências temporais em processos nos quais se considera além do cognitivo [...] os componentes estéticos e políticos da consciência histórica e da cultura histórica enquanto pré-requisitos, condições e determinações essenciais dos objetivos do aprendizado histórico" (RÜSEN, 2010, p. 48).

É óbvio que a assertiva acima se refere a processo mais complexo do que estamos abordando, no que se refere à formação da consciência histórica. O que indicamos é que as experiências temporais não estão vinculadas à ausência da escrita, ou da maturidade ou da dificuldade de entender o passado, pois o que se busca se refere a mudanças e processos aos quais se têm acesso pelos vestígios, fontes históricas, o que pode ser iniciado desde cedo. 
O que ainda não faz parte da compreensão das professoras nestes argumentos, conforme Blanch e Fernández (2010), Mattozzi (2010), Cooper (2012), dentre outros, é que no trabalho pedagógico cotidiano podemos, como professores, propiciar situações para a aprendizagem histórica por meio de experiências, linguagens, que propiciem a aplicação da métrica temporal articulada à ordenação, sucessão, mudança, simultaneidade, reconhecimento de ritmos temporais, memória, análise de fontes, narrativas sobre o cotidiano e em projeções para seu futuro. São estes e outros variados aspectos que compõem o tempo histórico, contribuindo para aproximações ao vocabulário que indica temporalidade e possibilita ir além na compreensão histórica.

Mas, será que as professoras já não buscam meios para a superação? Retomando a leitura das narrativas das 15 professoras em questão, constatamos que propiciar situações para o trabalho relacionadas com 0 cotidiano e História de vida, linha do tempo, História dos familiares (de onde vieram os avós, pais), História local, regional e literatura, fazem parte das indicações.

A literatura, como objeto de interesse pelas professoras para o Ensino de História, nos chamou atenção por nenhuma delas sequer cogitar interesse pela substituição do texto impresso pelo virtual. Como exemplo, podemos citar a professora Denise (65 anos), a qual tem a literatura como o estudo que a levou ao redimensionamento do Ensino de História, assim como outras duas professoras, que colocaram a literatura como parte das opções compatíveis para o Ensino de História, da seguinte forma:

\footnotetext{
"[...] com um livro 'O sítio no descobrimento' que trata do descobrimento com os personagens do sítio (Sitio do picapau amarelo) fazendo a viagem com Cabral. [...] as crianças tinham que criar um título para cada capítulo e ilustrar um livrinho. [...] Um dos meus alunos do $1^{\circ}$ ano foi muito bem. Ele até fez a carta do Caminha. Fez uma relação do tempo passado com o presente" (Patrícia, 41 anos).

"Eu apresento o que gosto no ensino: reis, coisas que fizeram até erradas, sem enfatizar muito o negativo, eu gosto de apresentar como 'conto de fadas'. [...] A história da Ruth Rocha sobre o descobrimento, contei em duas partes, e isso estimulou a curiosidade das crianças" (Catarina, 33 anos).
} 
O que temos são livros impressos de literatura assumindo importância para o Ensino de História sem apresentarem indicações de elementos históricos que os qualifiquem, a não ser a presença de datas, personagens, lugares, documentos e o não reconhecimento, pelas professoras, de que tal discurso literário está eivado pela ficção em que o narrador está vinculado ao tempo e espaço de sua produção.

Em abordagem contrária ao posto por Catarina, que quer apresentar a História como 'conto de fadas', a professora Ana (29 anos) deseja desmitificar acontecimentos ditos como históricos em nosso país, mas que são apresentados em abordagens equivocadas e/ou com omissões no que se refere à questão do negro e do índio. Para ela, é necessário apresentar a "[...] História contando a realidade, mesmo que cruel. Falo dos portugueses, da exploração, do abuso dos índios e negros".

São posições opostas que se aproximam na incompreensão da operação histórica e se afastam ao buscar a professora Ana, na História, explicação histórica que aborde diferenças e injustiças sociais, ainda que em entendimento prejudicado pelo fato de que nela "Persiste una tensión entre orientácion teórica y el alcance público de la historia" (KOCKA, 2002, p. 102).

Assim, mesmo que o entendimento das professoras contenha equívocos, as três buscam opções para o Ensino de História, acreditando que as crianças como ouvintes não serão passivas, pois:

[...] los niños se vem requeridos a reaccionar, confirmar, modificar o rechazar las ideas que ya poseen. El hecho de escuchar versiones diferentes de los cuentos, no sólo ayuda a aprender cosas sobre tiempos, lugares e personas ajenos a su própria experiência, sino también a compreender que no existe una única versión "correcta" del passado. (COOPER, 2002, p. 82).

O que se constata é que com maior ou menor reconhecimento do potencial da literatura e de outras ações e opções, que realizam e repercutem sobre o Ensino de História, elas permanecem engendrando esforços para a busca de alternativas, mudanças que propiciem uma aprendizagem histórica que, de uma forma ou outra, exponha os alunos à multiplicidade temporal das experiências humanas. 
Acreditando as quinze professoras que o Ensino de História é possível nos Anos Iniciais do Ensino Fundamental, o que constatamos se alinha aos estudos de Borghi (2010), que manifesta sua preocupação pela persistente falta de comunicação entre os ambientes acadêmicos e os escolares. Ao não ser o conhecimento histórico entendido como experiência que pode propiciar ao aluno outras formas de pensar o presente e o passado, em uma visão de conjunto para a articulação de pontos de vista, as professoras manifestaram, em relação aos saberes históricos, tanto incompreensões como o desejo de entendimento para mudanças em suas estratégias de ensino, perante o que vivenciaram como estudantes e o que realizam como professoras.

\section{Entre textos impressos e virtuais para o Ensino de História}

Giz, quadro e livro. Palavras que afloram para a designação de objetos entendidos como artefatos sempre presentes na cultura escolar e no ensino de História vivenciado pelas professoras. A permanência destes objetos nas aulas da segunda metade do século $X X$, assim como do século XXI, mesmo sendo presença que chama atenção por sua simplicidade não se torna irrelevante, por ser experiência partilhada por todas as professoras o que leva Catarina e Ignez (52 anos) a considerarem que para haver avanço é preciso que chegue às escolas públicas o "quadro digital".

Esta transferência da condição de 'agir' como dependente da tecnologia, ainda que relacionada a artefatos comuns, acontece em variados momentos ao não se considerar que "[...] o conteúdo informativo das ciências não pode, pois ser relevante sem mediações - só pode adquirir significação pelo desvio através das consequências práticas do progresso técnico" (HABERMAS, 2011, p. 95).

A ideia de progresso aparece tão articulada aos artefatos tecnológicos que de maneira naturalizada se insere nos argumentos das professoras em dois tempos; no passado, para indicar a presença de recursos que consideram normais e básicos, projetando como 'esperança de progresso' para o futuro a presença na escola da transformação trazida pelos artefatos tecnológicos ligados à era informacional. O 'temor' de ficar para 'trás', perante o acelerado avanço tecnológico, também está no 
horizonte de preocupações das professoras, paralelo à confiança de que a tecnologia:

"Na escola a tecnologia é muito boa [...] Infelizmente na minha escola isto não é possível. É uma briga para usar data show, computador, cada um tem que trazer o seu. O município está atrasado" (Luísa).

"Na escola está caminhando lentamente essas inovações dos artefatos tecnológicos. [...] vejo que o governo oferece muito pouco investimento nas escolas" (Natália).

"Se formos comparar a escola com o meu tempo de criança está legal. Mas se formos ver o mundo ainda é pouco. Eu acho que a escola ainda tem que se modernizar mais" (Patrícia).

"A escola inovou pouco (pública). A particular inovou bastante, quadro digital. [...] no futuro terá que ser como as escolas particulares." (Catarina).

As professoras manifestam preocupação relacionada à escola pública, o que gera sentimento de inadequação perante a ausência de recursos na consideração de que repercute sobre suas atribuições, o qual também traz temor sobre o desempenho de seu papel, pois:

"O professor terá que se preparar mais, estudar e ter tempo maior para preparar seu planejamento (aula) utilizando as novas tecnologias". (Denise, 65 anos)

"Tendo uma dificuldade em um conteúdo recorre à pesquisa no Google. Eu penso que [...] o professor vai ficar mais de lado. Ao mesmo tempo em que facilita, dificulta para o professor. Não há mais interferência do professor e do livro." (Cecília, 60 anos).

"Não sei se a escola estará preparada, uma vez que as crianças na 
sala já participam desta tecnologia. [...] Os professores deverão estar preparados. Não pode ser só tecnológico, pois perderá o papel principal (o professor), pois seremos um operador" (Ignez, 52 anos).

"[...] não sabemos usar a tecnologia como um todo. Falta saber fazer pesquisa segura, baixar músicas, vídeos. Os professores devem filtrar o que é seguro, pois sabemos que não há coisas verdadeiras na rede" (Marjorie, 47anos).

Relacionando esta expectativa aos recursos tecnológicos da atualidade (computador, internet, data show e outros) e a eles atribuindo as condições para aprendizagem, ancorada em pressupostos enraizados em universo escolar que não entende a História como "[...] tradução do passado ao presente, uma interpretação da realidade passada via uma concepção de mudança temporal que abarca o passado, o presente e a perspectiva dos acontecimentos futuros" (RÜSEN, 2007, p. 57), este grupo de 15 professoras, se impressiona com a tecnologia informática como texto, agregando, a ela, explicações para o afastamento que percebem em seus saberes históricos e suas práticas para ensino mais adequado à sociedade atual.

Do códex ao livro impresso pós-Gutenberg, há a permanência de características como folhas dobradas, sucessão de cadernos costurados uns aos outros, paginação e outras características dos livros. Para a atualidade, Chartier (1998, p. 12) indica diferenciações com a informática, que pouco a pouco, retira do livro a condição de objeto de manipulação ao ser substituído pela "[...] tela sobre a qual o texto eletrônico é lido, mas este objeto não é mais manuseado diretamente, imediatamente, pelo leitor" o que representa "[...] revolução nas estruturas do suporte material do escrito assim como nas maneiras de ler". (CHARTIER, 1998, p. 13).

Apontando o texto eletrônico como avanço, as professoras Laila (31 anos) e Antônia (35 anos) entendem que o livro impresso adquirirá novo status e maior eficiência ao ser transformado em memória eletrônica, o que propicia, dentre outras, a ausência de volume físico. A percepção de mudanças ocasionadas neste contato indireto, propiciado pela tela que 
separa o corpo do texto na leitura, assim como pelo tipo de fluxo sequencial, continuidade que não acontece como no livro encadernado, assim como as operações de produção que podem ser acumuladas, ainda não fazem parte do repertório das professoras.

Talvez, haja certo saudosismo nesta busca dos atributos do livro impresso em qualidades que o diferenciam do eletrônico, mas esta tentativa está relacionada à ausência da indicação do que é necessário aos dois tipos de suportes de leitura - a leitura crítica, não a profissional, mas aquela que para o Ensino de História favorece a "[...] apropriação inventiva da obra ou do texto que recebe" (CHARTIER, 1998, p. 19).

O que relacionamos ao pensamento das professoras é o fato de que os livros utilizados para o Ensino de História, ao se transformarem em textos eletrônicos, são 'superestimados' sem a consideração do potencial para a argumentação histórica, que não dependerá, em si, do suporte dado ao livro (impresso ou eletrônico), apesar das diferenças que contêm, ao depender a aprendizagem histórica de abordagem que propicie a presença das:

[...] estruturas categoriais do pensamento histórico e fornecer- Ihes meios linguísticos e intelectuais para relacionar conscientemente a própria situação com a história, e, portanto, colocarem-se em uma relação determinada para com o passado por meio de interpretações categoriais. (RÜSEN, 2012, p. 149-150).

É certo que não desconsideram a importância do professor na relação ensino-aprendizagem, pois os artefatos tecnológicos, incluindo-se os da informática, não são comentados como absolutos, mas sim que atribuem um poder de transformação em momento de transitoriedade que pode trazer o risco da "[...] informática acabar servindo apenas aos fins da própria informática e, talvez, não fazendo jus ao adjetivo 'educativo'" (COX, 2008, p. 31).

Em suas narrativas, as consequências da formação acadêmica se evidenciam, pois se foi em Pedagogia, fortaleceu saberes pedagógicos para escolas formais e não formais, com o enfraquecimento teórico e prático das disciplinas voltadas para os saberes específicos das diversas áreas de conhecimento. Por outro lado, se frequentaram a licenciatura, a maior 
fundamentação foi em conhecimentos teórico-metodológicos de sua área, distanciando-se do pedagógico. As duas características da formação estão presentes no grupo de professoras, pois 10 são pedagogas e cinco oriundas de diferentes licenciaturas, não aparecendo a formação em História para nenhuma.

Qual a dimensão atribuída pelas professoras ao Ensino de História em sua relação com os artefatos tecnológicos informacionais e textos impressos? Vejamos o que nos indicam:

"Buscar informações na internet para compararem o tipo de vida, o vestuário, música de uma região com outra região brasileira. Hoje somos privilegiadas com o uso dos meios de comunicação e com o conhecimento que as crianças trazem de casa. Os livros na atualidade contribuem mais com gravuras e menos escritos que no passado" (Denise).

"Os artefatos tecnológicos nos ajudam a não ser tão abstrato o ensino para o aluno. Podemos mostrar fotos, como era a casa da época explorada. Um exemplo é que podemos usar também na História de Londrina" (Marjorie).

"O professor tem que usar outros meios. Com a história é isto também. É você pesquisar como foi, como é, e pesquisar fotos, imagens. Infelizmente, para mim a tecnologia é um mal necessário. Quanto ao ensino de história, ensino e tecnologia, só o que vem do ensino mesmo, da aprendizagem" (Luísa).

Atribuir à internet a condição de fonte de informações não representa em si um equívoco, pois esta traz o distante e o imediato de forma competente. O que não é apontado pelas professoras é que a pesquisa não é simples compilação de dados que nos permite, literalmente, substituir o livro, o texto impresso pelo texto virtual, mas que exige possibilitar às pessoas em processo dinâmico, ações que permitam a compreensão, por meio da diferenciação, continuidade e interpretação, norteada por critérios que definem, delimitam e orientam questões para a aprendizagem histórica.

O que se constata é que o computador e a internet estão relacionados à pesquisa como instrumentos ágeis para o acesso ao conhecimento e 
informação, e que somente a professora Marjorie destaca a necessidade de crítica, considerando que: "Nosso papel é o de filtrar as coisas a serem repassadas para os alunos. Devemos desde o primeiro ano questionar e fazer com que a criança filtre o que é bom e ruim, tornando-o um ser crítico e pensante".

Outro aspecto ressaltado tem relação com as imagens inseridas como possibilidade de ampliação do conhecimento sobre o presente e o passado, principalmente por fotos, o que nos remete a situar, primeiramente, a questão das fontes históricas que também foram consideradas pelas professoras, ou seja, que a tecnologia informacional ampliaria a possibilidade da pesquisa no acesso facilitado às fontes históricas.

Ao não depositarem nas fontes virtuais uma capacidade indiscutível, são as imagens oriundas de gravuras, mapas, cartazes, vídeos, revistas e fotografias, o que consideram como fonte histórica facilitadora do ensino pelo acesso cotidiano a variados tipos de produção e suporte. Oito professoras, em suas argumentações, não trouxeram situações de reconhecimento do que a fonte histórica pode significar para o Ensino de História. Neste contexto, Marjorie entra como voz dissonante ao considerar que: "Os artefatos tecnológicos nos ajudam a não ser tão abstrato o ensino para o aluno. Podemos mostrar fotos, como era a casa da época explorada".

A fotografia é a mais citada como fonte relacionada ao Ensino de História e à presença do computador ou artefatos tecnológicos informacionais, assim como ao passado, em entendimento de que tal recurso pode trazer objetividade para a História perante a maciça produção técnica. Assim, se atribui ao instrumento computador e suas aplicabilidades a força mágica para interferir, mudar aquilo que, de certa forma, está constituído na 'objetividade' da existência dessas produções tecnológicas. Nesta perspectiva, Antônia soma ao colocar que: "A tecnologia de artefatos virou sinônimo de computador. Acho que tem tempo histórico antes da internet e depois da internet. Marco histórico - antes pesquisava na biblioteca, na Barsa. 'Agora temos Google'".

Da maneira exposta temos os textos virtuais, fotografias e filmes 
como presença no Ensino de História ligadas, ora ao progresso da informática, ora às fontes históricas e ora à possibilidade de melhorar, em si, o Ensino de História. O acesso, ainda limitado, preocupa Luísa e Marjorie por ampliar a desigualdade, assim como, fortalece a tendência à padronização e à homogeneização. Tal questão se coaduna com a preocupação de Hobsbawm (2000) que aponta no processo técnico da globalização, a exigência da 'padronização e homogeneização' como

"[...] um dos grandes problemas para o século XXI [...] definir qual o nível máximo de homogeneidade, além do qual haveria uma reação aversiva, e em que medida esse processo pode ser compatibilizado com a diversidade presente no mundo" (HOBSBAWM, 2000, p. 75).

\section{Considerações Finais}

Apresentamos alguns elementos do pensamento histórico das professoras que repercutem sobre o Ensino de História e que nos demonstram a diversidade de abordagens e sentidos atribuídos à História e ao seu ensino, em relação aos artefatos tecnológicos, no caso, o texto impresso e virtual.

A aceleração tecnológica que incomodava no século XIX certamente não é a do século XXI, ao gerar para a atualidade a volatilidade de mercadorias que trazem sobrecarga sensorial, dominada pela efemeridade, manipulação do gosto, da opinião e fragmentação que repercute em 'temores' que são reconhecidos pontualmente. Este contexto leva as professoras a atribuírem à tecnologia informacional um poder que, em sua ausência, gera atraso na escola (em recursos tecnológicos) e nas professoras (em conhecimentos tecnológicos). Tal compreensão não apresenta, de forma clara, o entendimento de que não será no depósito de expectativas sobre as tecnologias para o Ensino de História o que poderá promover mudanças, e que a presença e a manipulação técnica adequada, deste ou daquele recurso, não serão suficientes para a determinação de transformações.

Neste contexto, as más condições de trabalho e o suporte tecnológico escasso emergem como os justificadores de carências para as professoras, 
que acrescem a este contexto as dificuldades para a aprendizagem pelos alunos construindo, assim, um arcabouço de justificativas e obstáculos para o Ensino de História.

A experiência do tempo e espaço que requer a 'orientação do agir', não acontece de maneira uniforme, adquirindo formas objetivas $e$ subjetivas, dependentes em variados aspectos da cultura de onde se fala assim os elementos de compreensão da aprendizagem histórica, enunciadas pelas professoras, necessitam ser aprofundadas em suas especificidades, como é o caso das fontes históricas; historiografia e livros didáticos; História local, assim como no que se refere às atividades de sala de aula como linha do tempo, datas comemorativas, pesquisa e questionários, dentre outras.

Este estudo, ao se caracterizar como um reconhecimento de elementos que compõem a consciência histórica de 15 professoras atuantes nos Anos Iniciais do Ensino Fundamental nos trouxe a necessidade da continuidade, o que acontece no desenvolvimento do projeto de pesquisa: "NARRATIVAS E FORMAÇÃO DE PROFESSORES: mediando ressignificações para a aprendizagem e o Ensino de História nos Anos Iniciais do Ensino Fundamental", que visa propiciar situações de reflexão em encontros semanais com as professoras, abordando novos horizontes pedagógicos voltados aos saberes e fazeres docentes, perante as exigências que se apresentam com os avanços tecnológicos e outras demandas da sociedade atual para o Ensino de História.

\section{Referências}

BÉDARIDA, François. As responsabilidades do Historiador expert. In: BOUTIER, Jean; JULIA, Dominique. Passados recompostos: campos e canteiros da História. Rio de Janeiro: Editora UFRJ; Editora FGV, 1998. p.145-153.

BLANCH, Joan Pagès; FERNÁNDEZ, Antoni Santisteban. La ensenanza y el aprendizaje del tempo histórico em la educación primaria. Caderno CEDES, Campinas, n. 82, p. 281-309, set./dez. 2010.

BORGHI, Beatrice. Las fuentes de la historia entre investigación y didáctica. In: RUIZ, Rosa M. Ávila; GRACIA, M. Pilar Rivero; SANZ, Pedro L. Dominguez. Metodologia de investigación em didáctica de las ciencias sociales. Zaragoza: Institución Fernando El Católico (C.S.I.C), 2010. p.75- 
84.

CHESNAUX, Jean. Modernidade-Mundo. 2.ed. Petrópolis: Vozes, 1996.

COOPER, Hilary. Didáctica de la historia em la educación infantil y primaria. Madrid: Ministério de Educación, Cultura Y Deporte; Ediciones Morata, 2002.

CERTEAU, Michel de. A escrita da história. 2. ed. Rio de Janeiro: Forense Universitária, 2007.

CHARTIER, Roger. A história ou a leitura do tempo. 2. ed. Belo Horizonte: Autêntica Editora, 2010.

CHARTIER, Roger. A aventura do livro: do leitor ao navegador. São Paulo: Imprensa Oficial do Estado de São Paulo: Editora UNESP, 1998.

COX, Kenia Kodel. Informática na educação escolar. 2. ed. Campinas: Autores Associados, 2008.

HABERMAS, Jürgen. Técnica e ciência como ideologia. Lisboa: Edições 70, 2011.

HOBSBAWM, Eric. O novo século. São Paulo: Companhia das Letras, 2000.

KOCKA, Jürgen. Historia social y conciencia historica. Madrid: Marcial Pons, Ediciones de Historia S.A, 2002

KOSELLECK, Reinhart. Los estratos del tempo: estudios sobre la historia. Barcelona: Ediciones Paidós Ibérica S. A., 2001.

KOSELLECK, Reinhart. Futuro passado: contribuição à semântica dos tempos históricos. Rio de Janeiro: Contraponto: Ed. PUC-Rio, 2006.

LAHIRE, Bernard. Homem plural: os determinantes da ação. Petrópolis: Editora Vozes, 2002.

LE GOFF, Charles. História e memória. 5. ed. Campinas: Editora da UNICAMP, 2003.

MATTOZZI, Ivo. La investigación sobre didáctica de la Historia como diálogo entre investigación teórica e investigación aplicada. In: RUIZ, Rosa M. Ávila; GRACIA, M. Pilar Rivero; SANZ, Pedro L. Dominguez. Metodologia de investigación em didáctica de las ciencias sociales. Zaragoza: Institución Fernando El Católico (C.S.I.C), 2010. p.95-104.

RÜSEN, Jörn. Razão histórica: teoria da história: os fundamentos da ciência histórica. Brasília: UNB, 2001.

RÜSEN, Jörn. História viva: teoria da história III: formas e funções do conhecimento histórico. Brasília: UNB, 2007.

RÜSEN, Jörn. Jörn Rüsen e o ensino de história. Curitiba: Ed. UFPR, 2010. 
RÜSEN, Jörn. Aprendizagem histórica: fundamentos e paradigmas. Curitiba: W. A. Editores, 2012.

Recebido em 23 de dezembro de 2018 Aprovado em 14 de janeiro de 2019 